\title{
The Implementation of Supply-side Structural Reform: Next Chapter for High-Tech Development Zones
}

\author{
Di $\operatorname{Tian}^{1}$ \\ ${ }^{1}$ Culver Academies, 1300 Academy Rd., Culver, IN, 46511, USA
}

\begin{abstract}
Promoting supply-side structural reform is the key to China's economic transformation and upgrading. As disruptive innovation is affecting different sectors and areas of society, numerous high-tech development zones should fully release their vitality and realize unprecedented development while contributing to this reform. This study attempted to further analyze the Research and Development (R\&D) efficiency of high-tech zones in the past mode, and shed light on a more advanced and effective development pattern in the near future. This paper used Data Envelopment Analysis (DEA) model, which is a linear programming method to measure the efficiency between multiple decision-making units, and categorized three decisive factors to reach solid conclusions [1]. Our statistical results indicated that the low R\&D efficiency is ubiquity among high-tech industries, and there is not yet a strong platform for advanced $R \& D$ activities. Lastly, this paper suggested strategies to maintain the sustainable development of the high-tech industry under the supply-side reform.
\end{abstract}

\section{Introduction}

From a global point of view, the high-tech development zones in many developed countries have achieved from external-cause motivation to inner mobility. The Silicon Valley in the United States, and the Sophia Antipolis Indianapolis park in France are the two brilliant examples, representing the advanced nature of high-tech zones. The Silicon Valley was benefited from the democratization movement among various campuses in the United States campus [2], while the Sophia Antipolis Indianapolis park resulted from the famous French "decentralization" movement [3]. It is obvious to conclude that the penetration of the social environment oriented by innovation and entrepreneurship is the internal driving force for the transformation of high-tech zones.

Throughout the local high-tech zones in China, six of them have been approved to enter the national "first-class zone" (Beijing-Zhongguancun Science park, ShanghaiZhangjiang High-tech Zone, Wuhan-Donghu High-tech Zone, Shenzhen High-tech Zone, Chengdu High-tech Zone, and Xi'an High-tech Zone) [4]. At present, most of the high-tech zones are still in the process of gathering and spreading factors of productions. Therefore, this paper will use the DEA model to discuss the efficiency of science and technology innovation in these high-tech zones, along with three decisive factors. Through this statistical model, any high-tech zones that are of similar development stage and paradigm can be directly comparable based on observations and historical data. This study aims to provide a general guide to help hightech zones to integrate available resources and to attain maximum efficiency.

\section{Methodology}

This paper mainly analyzed the possible impact on R\&D efficiency from two aspects: R\&D investment intensity and government policy. Firstly, this section searched the relevant data of high-tech parks from 2015 to 2020, and computed R\&D efficiency through input-output analysis. Secondly, based on the calculated efficiency, this paper conducted a statistical relationship between three influencing factors and their effects of the R\&D efficiency on high-tech industrial parks.

This paper adopted the DEA model based on the following reasons [5]:

- DEA can evaluate the relative efficiency of decision-making units with multiple inputs and outputs;

- There is no need to consider the unification of dimensions;

- The calculated efficiency is the maximum value, which does not need to consider the weight of each index. This simplification is effective to avoid the subjective assumptions and remain objective in judgment.

Next, this paper would focus on the definition of input and output of R\&D activities in high-tech zones. This paper selected R\&D expenditure and scientific/technological personnel as input, while the scientific and technological income as output. The data set is retrieved from China Torch Statistical Yearbook from 2015 to 2020. During this period, the high-tech industrial development zones in China have increased from 56 (end 
of the year 2015) to 169 (end of the year 2019) [6]. To ensure the continuity and integrity of statistics, this paper selected 56 approved high-tech development zones in 2013 as the research objects.

\section{Test Results and Discussions}

\subsection{Data Set}

Table1. Input \& Output of R\&D Activities

\begin{tabular}{|c|c|c|c|c|c|}
\hline $\begin{array}{c}R \& D \\
\text { Efficiency }\end{array}$ & 2015 & 2016 & 2017 & 2018 & 2019 \\
\hline Beijing & 0.51 & 0.38 & 0.54 & 0.48 & 0.31 \\
\hline Tianjin & 0.59 & 0.37 & 0.52 & 0.44 & 0.31 \\
\hline Shijiazhuang & 0.27 & 0.37 & 0.56 & 0.41 & 0.36 \\
\hline Baoding & 0.00 & 0.00 & 0.00 & 0.00 & 0.00 \\
\hline Taiyuan & 0.26 & 0.18 & 0.27 & 0.19 & 0.16 \\
\hline Baotou & 0.09 & 0.05 & 0.07 & 0.06 & 0.05 \\
\hline Shenyang & 0.78 & 0.53 & 0.68 & 0.41 & 0.36 \\
\hline Dalian & 0.34 & 0.32 & 0.46 & 0.29 & 0.24 \\
\hline Anshan & 0.32 & 0.26 & 0.34 & 0.26 & 0.24 \\
\hline Changchun & 0.08 & 0.02 & 0.12 & 0.03 & 0.36 \\
\hline Jilin & 0.10 & 0.07 & 0.08 & 0.07 & 0.05 \\
\hline Harbin & 0.03 & 0.02 & 0.04 & 0.02 & 0.20 \\
\hline Daqing & 0.24 & 0.18 & 0.24 & 0.34 & 0.39 \\
\hline Shanghai & 0.16 & 0.23 & 0.30 & 0.18 & 0.12 \\
\hline Nanjing & 0.07 & 0.06 & 0.07 & 0.06 & 0.05 \\
\hline Changzhou & 0.01 & 0.01 & 0.03 & 0.02 & 0.04 \\
\hline Wuxi & 0.01 & 0.03 & 0.06 & 0.04 & 0.03 \\
\hline Suzhou & 0.21 & 0.19 & 0.29 & 0.17 & 0.13 \\
\hline Taizhou & 0.02 & 0.03 & 0.06 & 0.05 & 0.05 \\
\hline Hangzhou & 0.69 & 0.40 & 0.54 & 0.39 & 0.33 \\
\hline Ningbo & 0.51 & 0.34 & 0.04 & 0.37 & 0.30 \\
\hline Hefei & 0.25 & 0.05 & 0.05 & 0.15 & 0.26 \\
\hline Fuzhou & 0.07 & 0.04 & 0.05 & 0.03 & 0.06 \\
\hline Xiamen & 0.02 & 0.02 & 0.01 & 0.04 & 0.03 \\
\hline Nanchang & 0.05 & 0.05 & 0.10 & 0.08 & 0.05 \\
\hline Jinan & 1.00 & 0.66 & 0.82 & 0.58 & 0.36 \\
\hline Qingdao & 0.05 & 0.02 & 0.01 & 0.01 & 0.01 \\
\hline Zibo & 0.28 & 0.20 & 0.27 & 0.19 & 0.16 \\
\hline Huangfang & 0.04 & 0.02 & 0.02 & 0.10 & 0.09 \\
\hline Weihai & 0.01 & 0.01 & 0.01 & 0.00 & 0.00 \\
\hline Zhengzhou & 0.12 & 0.09 & 0.50 & 0.10 & 0.09 \\
\hline Luoyang & 0.25 & 0.33 & 0.22 & 0.15 & 0.15 \\
\hline Wuhan & 0.22 & 0.15 & 0.32 & 0.25 & 0.26 \\
\hline Xiangfan & 0.37 & 0.34 & 0.44 & 0.25 & 0.21 \\
\hline Changsha & 0.02 & 0.05 & 0.07 & 0.07 & 0.09 \\
\hline
\end{tabular}

\begin{tabular}{|c|c|c|c|c|c|}
\hline Zhuzhou & 0.01 & 0.01 & 0.00 & 0.01 & 0.02 \\
\hline Xiangtan & 0.00 & 0.01 & 0.02 & 0.00 & 0.00 \\
\hline Guangzhou & 0.51 & 0.33 & 0.39 & 0.26 & 0.22 \\
\hline Shenzhen & 0.01 & 0.01 & 0.13 & 0.20 & 0.19 \\
\hline Zhuhai & 0.06 & 0.02 & 0.04 & 0.02 & 0.03 \\
\hline Huizhou & 0.00 & 0.00 & 0.00 & 0.00 & 0.00 \\
\hline Zhongshan & 0.00 & 0.01 & 0.05 & 0.37 & 0.32 \\
\hline Foshan & 0.03 & 0.01 & 0.02 & 0.01 & 0.10 \\
\hline Nanjing & 0.59 & 0.39 & 0.39 & 0.30 & 0.26 \\
\hline Guilin & 0.01 & 0.01 & 0.03 & 0.01 & 0.32 \\
\hline Hainan & 0.00 & 0.01 & 0.02 & 0.00 & 0.00 \\
\hline Chengdu & 0.19 & 0.14 & 0.42 & 0.33 & 0.39 \\
\hline Chongqing & 1.00 & 1.00 & 1.00 & 0.69 & 0.52 \\
\hline Mianyang & 0.00 & 0.00 & 0.01 & 0.00 & 0.00 \\
\hline Guiyang & 0.07 & 0.07 & 0.16 & 0.05 & 0.03 \\
\hline Kunming & 0.07 & 0.08 & 0.11 & 0.07 & 0.11 \\
\hline Xi'an & 0.48 & 0.37 & 0.56 & 0.26 & 0.20 \\
\hline Baoji & 0.01 & 0.01 & 0.00 & 0.01 & 0.01 \\
\hline Yanglin & 0.00 & 0.00 & 0.01 & 1.00 & 1.00 \\
\hline Lanzhou & 0.11 & 0.10 & 0.78 & 0.18 & 0.46 \\
\hline Urumqi & 0.15 & 0.14 & 0.37 & 0.65 & 0.13 \\
\hline
\end{tabular}

\subsection{Results and discussions}

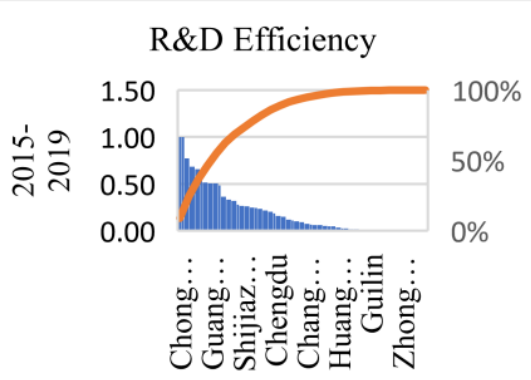

High-Tech Zones

Fig1. High-Tech Zones R\&D Efficiency

The results show that the R\&D efficiency of China's high-tech industrial development zones has the following features:

The overall R\&D efficiency of high-tech industrial zones is relatively low, with huge regional disparity. Compared with the investment and outcome of capital assets, the main reason here is the excessive expenditure and underused funds.

The sources of R\&D funds can be divided into government funds, social (enterprise) funds, foreign funds, and other funds. Government funds occupied more than $50 \%$, and most of them were allocated with specific industry support plans. However, the inefficient utilization (such as resource mismatch) led to a lower input-output ratio, even far away from the average optimal paradigm. 


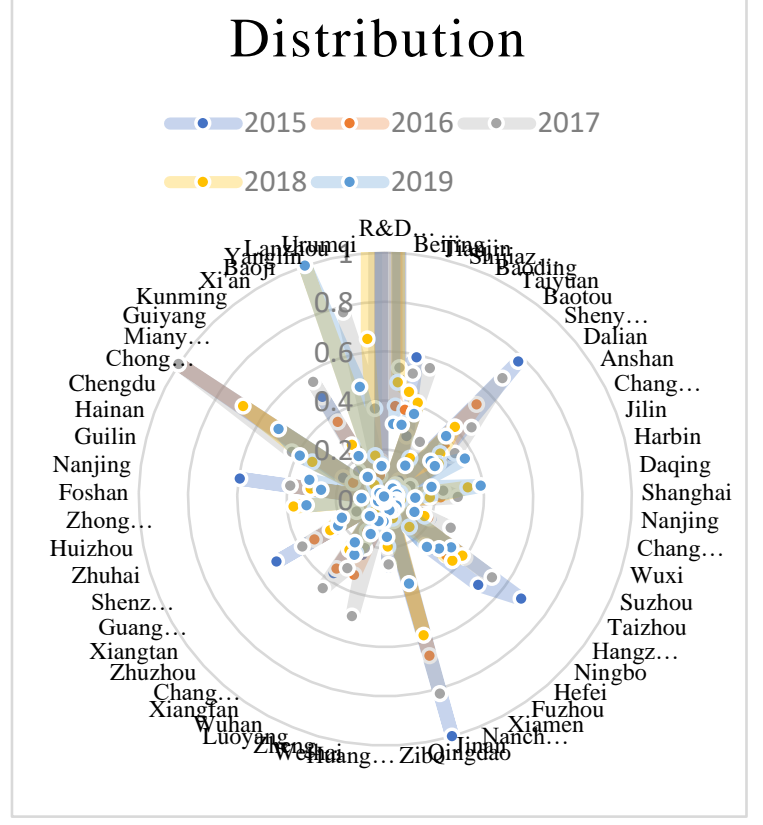

Fig2. R\&D Funds Distribution

\section{Decisive Factors}

To better understand the possible impact of decisive elements on the overall efficiency of R\&D inputs, this paper mainly selects three factors as follows. This section used regression analysis in this section to measure the statistical effects of the capital input and government orientation on R\&D efficiency of high-tech industrial zones in China.

\subsection{Symbol Explanation}

Table2. Elements that Impact R\&D efficiency

\begin{tabular}{lll}
\hline Abbreviation & Index & Unit \\
\hline R\&D & For $\mathrm{i}$ th region, the & Percentage \\
& proportion of R\&D \\
& expenditure of the total \\
& revenue of high-tech \\
& industry in the T year \\
& The proportion of financial Percentage \\
& appropriation for high-tech \\
GOV & zones of the total amount \\
& raised for science and \\
& technology \\
& Log value of the gross / \\
& industrial product \\
\hline
\end{tabular}

\subsection{Regression Results}

\begin{tabular}{cl} 
Efficiency $=A_{0}+A_{1} R \& D+A_{2} G O V+A_{3} P R O$ \\
\hline R\&D & Correlation Index \\
GOV & -0.1515 \\
PRO & -0.1230 \\
\hline
\end{tabular}

The above empirical results revealed that the $R \& D$ investment intensity has a negative impact on $R \& D$ efficiency, that is, when the proportion of R\&D expenditure in technical income increases, the $R \& D$ efficiency would decrease. This is consistent with the results measured by the DEA model in the first section. This negative effect verified that there is indeed an excessive investment in R\&D activities of high-tech industrial zones in China, and these funds are not effectively utilized.

Meanwhile, the proportion of financial allocation in the total science and technology funds in the high-tech zones has a negative impact on R\&D efficiency, too. This indicated that the government fails to play an active role in R\&D activities. For example, there is a matching error between the planned direction (the key supporting enterprises) and the market demand.

\section{Conclusion}

The formation of high-tech zones requires adequate resources, such as knowledge capital, social capital, and organizational capital [7]. The top-down model can accelerate the development process of high-tech zone clusters. But, under the macroeconomic background of supply-side structural reforms, most of the high-tech industrial zones are shifting from industry-led to innovation-driven, the bottom-up mode will become the crucial push to promote the sustainable development of high-tech zones. Market forces can increase the conduit of resource flows from over-supplied side to supply-behind side, from low efficiency of enterprises to high efficiency of enterprises.

In conclusion, the most effective social environment of the high-tech zones lies in the complementation of the government and the market. It is not supposed to be dominated by the government, asserting their authority to have a greater say on the structural adjustment. The reform also needs to respect the market regulations, bring the market into full play, and reduce to the maximum extent the level of government interference in economic activities [8]. Although there is still a long way to improve the market mechanism, our conclusion remains positive that the path of "supply-side reform" to promote economic restructure adjustments and transformation is full of hope.

\section{Acknowledgment}

The author hopes to acknowledge the great support of Professor Li's project supervisor at Carnegie Mellon University. The professor has guided the author to solve modeling and data analysis issues and persist in completing the project.

\section{References}

1. K. Vincová, Ing. "Using DEA Models To Measure Efficiency". Nbs. Sk. https://www.nbs.sk/ img/Documents/BIATEC/BIA0 8_05/24_28.pdf. 2005 .

2. H. Chris. "A Brief History Of Silicon Valley, The Region That Revolutionizes How We Do Everything". Entrepreneur. https://www.entrepreneur.com/article/240534. 2020. 
3. L.Pierre.Globalforum.Items-Int.Com. http://globalforum.items-int.com/gf/gfcontent/uploads/2014/04/8_Birth_of_a_city_SOPHI A_ANTIPOLIS.pdf. 1989.

4. T. Tangwei, et al. Research on the new path of transformation national high-tech zone -- From the Perspective of world-class science parks [J]. Science and technology progress and countermeasures, 2013, 05:31-36. (in Chinese)

5. B.P.Sandra and B. Peter and D. R. Morales. "Feature Selection In Data Envelopment Analysis: A Mathematical Optimization Approach."2019.

6. China Torch Official Website. http://www.chinatorch.gov.cn/kjfw/index.shtml. 2020.

7. C. Hongzhuan and S.Liangliang, et al. The inputOutput efficiency evaluation of China's high-tech industrial zones based on the DEA model [J]. Science of Science and Management of Science and Technology,2013,04:104-109. (in Chinese)

8. W. Jinglian, et al. Supply-side reform cannot be interpreted into administrative force adjustments [J]. Finance \& Economics, 2016, 03:49-50. (in Chinese) 